\title{
Factors Affecting Demand and Utilization of Dental Services: Evidence from a Developing Country
}

\author{
Soraya Nouraei Motlagh (iD ${ }^{1}$, Saman Ghasempour ${ }^{2}$, Razyeh Bajoulvand ${ }^{3}$, Sara Hasanvand ${ }^{3}$, Sheida \\ Abbasi-Shakaram ${ }^{3}$ and Mohammad Hasan Imani-Nasab ${ }^{1,}$ \\ ${ }^{1}$ Social Determinants of Health Research Center, Lorestan University of Medical Sciences, Khorramabad, Iran \\ ${ }^{2}$ Department of Health Economics, School of Health Management and Information Sciences, Iran University of Medical Sciences, Tehran, Iran \\ ${ }^{3}$ Student Research Committee, Lorestan University of Medical Sciences, Khorramabad, Iran \\ Corresponding author: Social Determinants of Health Research Center, Lorestan University of Medical Sciences, Khorramabad, Iran. Email: imani_mh@yahoo.com
}

Received 2019 January 12; Revised 2019 April 30; Accepted 2019 May 10.

\begin{abstract}
Background: To achieve evidence-based policymaking to improve access to dental services and reduce inequality in the utilization of these services, the identification of effective factors on the use of dental services is essential.

Objectives: Therefore, the present study was conducted to investigate the most important socioeconomic factors affecting the demand and utilization of dental services among households in Khorramabad, Iran.

Methods: This cross-sectional study was performed among 500 households in Khorramabad city in 2017. The participants were selected using a randomized stratified sampling method. Logistic regression was used to determine the most important factors affecting the utilization of dental services and linear regression to examine income elasticity. To measure inequality among income groups, the concentration index was employed. Data analysis was performed using STATA-14 software and the inequality measurement was carried out using DASP-2.3 in STATA software.

Results: The mean number of visits by the respondents was $2.78 \pm 1.8$. Income elasticity and concentration index for these services were estimated to be 0.31 and 0.207 , respectively. Increasing household income, advancing age, higher education level of the head of the household, and having complementary insurance coverage $(\mathrm{OR}=1.72)$ had positive relationships with the increased utilization of dental services. Also, a female head of the household $(\mathrm{OR}=0.39)$ and increased household size $(\mathrm{OR}=0.9)$ led to a reduction in the utilization of these services.

Conclusions: Inequality is observed in the use of dental services between different socioeconomic groups. Therefore, health policymakers should implement interventions such as dental health insurance to reduce this inequality in such a way that inequalities between socioeconomic groups are reduced.
\end{abstract}

Keywords: Dental Services, Utilization, Socioeconomic Factors, Iran

\section{Background}

Evidence suggests that oral health and the coverage of its services are not suitable worldwide, especially in developing countries (1) such that $5 \%-20 \%$ of adults show signs of gingivitis (2). The average coverage of oral and dental care is $58.4 \%$ worldwide and $48.5 \%$ in developing countries (1). However, dental services are considered expensive health services, with oral diseases being the fourth most expensive diseases $(3,4)$. The direct financial burden of dental services in the world is estimated at $\$ 298$ billion per year (5). In Iran, dental services impose the highest health expenditures second to admission services. The share of outof-pocket expenditures for dental services in Iran has been reported at around $90 \%$ (6). In Iran, dental services are mainly provided by the private sector (7) such that about $80 \%$ of dentists in Iran work in the private sector and only $20 \%$ in the public sector (8).

Reducing inequality in access and utilization of health services is an important goal of health systems. Although full equality in the utilization of these services is impossible, policymakers can design and implement interventions to reduce these inequalities (9). Although the health system of Iran could reduce inequality in access to some services, such as public health and vaccination, evidence suggests that there is considerable inequality in services such as dentistry among different groups despite that oral health is an important component of public health and quality of life for the community (10-12). Since 1997, some dental services, such as teeth cleaning and restoration, 
have been added to primary health care in rural areas of Iran (13). However, due to the lack of coverage of most dental services by basic insurance, patients have to pay for them directly (9) and access to these services, because of high costs, imposes a significant financial burden on patients, their families, the health system, and the entire community (7). The most important barrier to access to dental services seems to be economic barriers. Continuation of this process can lead to more serious health problems and the increased risk of facing catastrophic expenditures (14).

Evidence suggests that economic factors are not the only factors affecting the demand and utilization of dental care services, but there are also factors such as race, age, gender, parental education level, health literacy level, people's attitudes, family income, insurance status, geographical location, and socio-cultural factors that can affect access to educational services, preventive care, and dental services (15-17). In addition, having dental insurance coverage is one of the main determinants of demand and utilization of these services (18). The results by Andkhoie et al. (18) showed that Canadian household income elasticity for the demand for dental services was 0.146. In this study, lowerincome groups, due to full health insurance coverage, had the highest chance of paying for dental care (18).

The results by Guiney et al. in Ireland also indicated that income, employment status, education level, place of residence, and vehicle ownership were good predictors of the utilization of dental services (19). The results of a crosssectional study in a city in Iran (2010) indicated that less than $50 \%$ of people with oral and dental problems visited dentists (20). The results of a study by Rezai et al. among households from Sanandaj(Iran) in 2015 indicated that the average frequency of dental visits was 1.9 times per year, with $61.9 \%$ of them referring to a dentist at least once a year. The results of the regression study showed that factors such as income, education level, and employment status could affect the utilization of dental services (7). Besides, in a cross-sectional study among clients visiting dental offices in Ramsar (2017), only had 6.6\% supplementary insurance. Moreover, $91 \%$ of the participants had referred to receive treatment services and only had $9 \%$ of them visited dental centers for check-ups. The results of this study showed that despite the advancement of basic and supplementary insurance coverage, the main part of dental care expenditures was out-of-pocket (14).

A review of the literature shows that social factors affecting health, such as age, sex, race, ethnicity, geography, income, education, and employment, can affect the demand and utilization of dental care. To reduce the inequalities in dental services, health policymakers, especially in developing countries, need information on de- mand and utilization of dental care and determining factors. Although several studies on the utilization of dental services in developing countries, including Iran, have been published, further studies are needed to determine the different dimensions of demand and utilization of these services and to gain a better understanding of the factors affecting them $(8,10)$.

\section{Objectives}

Therefore, to fill the existing gap for informed policymaking in the field of dental services, the current study aimed to investigate socioeconomic factors affecting the demand and utilization of dental services among households in Khorramabad city in 2017. Considering the implementation of the Health Promotion Plan in Iran's health system in recent years, this study can provide evidence regarding the effects of this plan on the demand and utilization of dental services.

\section{Methods}

This cross-sectional study employed a multi-stage sampling method to obtain information on the utilization of dental services in 500 households in Khorramabad city in 2017. Sampling was performed using the stratified random sampling method at two stages. At the first stage, all urban health centers and all health units of Khorramabad city were defined as strata and the numbers of households covered by these centers were determined. Then, the sample size of each stratum was determined by the allocation method proportional to the share of the population. In the second stage, in each of the strata, random sampling was implemented and the sample households were selected using their file numbers. The required information was collected through a self-administered questionnaire whose reliability and validity were confirmed in previous studies $(7,10)$. This questionnaire included two sections. The first section was to gather the main sociodemographic features of participants, comprising age, level of education, income level, gender, household size, employment status, and health insurance coverage (supplementary and basic). The second section of the questionnaire was used to record the demand and utilization of dental care services.

In this study, the demand for dental services was assessed using two different models, namely linear regression and logistic regression. First, the dependent variable was analyzed using univariate methods. Then, the significant variables in the previous stage were included in the multivariate analysis. At the first stage, the linear regression model was used to estimate the income elasticity of 
households in Lorestan concerning dental services, which was based on the study by Grytten et al. (21). The logarithm of household dental expenditures was considered as a function of the logarithm of total household expenditures. We used a two-way logarithmic model in this study, which is a standard approach in economic analyses. The linear regression model was as follows:

Lndental-expenditures $=\mathrm{F}$ (Intotal-expenditures, Insurance, demographic, HHS, NE)

where "insurance" is defined as having full supplementary and basic insurance coverage, "demographic" denotes the demographic characteristics of households including age, gender, and education level of the head of the household, HHS is the household size, and NE denotes the number of employed household members and the occupational status of the head of the household. The selection of all variables was based on the literature $(21,22)$.

The second model used in this study was the logistic regression model. The logistic model is used in cases where the dependent variable is dichotomous. In this research, the dependent variable (i.e., demand for dental services) was dichotomous (lack of demand for dental services $=0$ and demand for dental services $=1$ ). If we consider $\mathrm{P}_{\mathrm{i}}$ as the likelihood of demand and $1-\mathrm{P}_{\mathrm{i}}$ as the likelihood of nondemand for dental services, the Logit model is as follows:

$\operatorname{Ln}\left(\frac{P_{i}}{1-P_{i}}\right)$

$=F($ lnexpenditure, Insurance, demographic, $H H S, N E)$

Using this model, we first obtained the likelihood of demand and referral for dental services by individuals and in the next step, we obtained the marginal effects of each explanatory variable. The marginal effect showed for a unit increase in explanatory variables, how much the likelihood of the occurrence of the dependent variable, that is, the increased demand and referral for dental services, would change.

In the final stage, to measure inequality in the utilization of dental care services, a concentration curve for receiving these services was plotted. In this curve, the cumulative percentage of paid dental care expenditures in the $y$-axis was compared to the cumulative percentage of the population based on income in the X-axis. However, the concentration curve does not indicate the amount of inequality in the utilization of health services. Therefore, the concentration curve is used to measure the concentration index, which is twice the area between the equality line and the concentration curve. If there was no inequality in the utilization of health services between income groups, the index value would be zero. When the concentration curve was above the equality line (line 45), it indicated that the concentration index was negative and the concentration of dental service expenditures was in the interest of the poor while if the concentration line was below the equality line, it indicated that the concentration index had positive values and the financing of these services was concentrated to the benefit of the rich (23-25).

\section{Results}

Of the households surveyed, $91.82 \%$ had male heads and the rest had female heads (Table 1 ). The mean age of the heads of households was $48.86 \pm 13.38$ years $(48.29 \pm 13.47$ years for men and $55.21 \pm 10.41$ years for women). The majority of the participants (45.9\%) had secondary education. Monthly income in $73.71 \%$ of the households was less than 20 million Iranian Rials. Also, 84.03\% and $25.95 \%$ of the participants had basic health insurance and supplementary health insurance coverage, respectively.

\begin{tabular}{|c|c|}
\hline Socioeconomic Characteristics of Household Heads & Findings \\
\hline \multicolumn{2}{|l|}{ Age category, $y$} \\
\hline$<30$ & $25(4.99)$ \\
\hline $30-50$ & $237(47.31)$ \\
\hline $50-65$ & $176(35.13)$ \\
\hline$>65$ & $63(12.57)$ \\
\hline \multicolumn{2}{|l|}{ Gender } \\
\hline Male & $460(91.82)$ \\
\hline Female & $41(8.18)$ \\
\hline \multicolumn{2}{|l|}{ Insurance coverage } \\
\hline Yes & $421(84.03)$ \\
\hline No & $80(15.97)$ \\
\hline \multicolumn{2}{|l|}{ Supplementary insurance coverage } \\
\hline Yes & $130(25.95)$ \\
\hline No & $371(74.05)$ \\
\hline \multicolumn{2}{|l|}{ Education level } \\
\hline Illiterate & $51(10.18)$ \\
\hline Primary school & $76(15.17)$ \\
\hline Secondary school & $230(45.9)$ \\
\hline University graduate & $144(28.74)$ \\
\hline \multicolumn{2}{|l|}{ Monthly income, Rials } \\
\hline$<20$ million & $370(73.71)$ \\
\hline 20-30 million & $90(17.93)$ \\
\hline$>30$ million & $42(8.37)$ \\
\hline
\end{tabular}

${ }^{\mathrm{a}}$ Values are expressed as No. (\%).

The income elasticity for dental services was 0.31 . The findings related to the most important determinants of 
dental service utilization are summarized in Table 2. According to the findings, $30.25 \%$ of the participants did not receive dental services despite the need for treatment, of whom $60 \%$ mentioned the high expenditures of these services as the main reason. The mean number of visits by the participants was $2.78 \pm 1.8$. Overall, $54.12 \%$ of the respondents reported one or two dental visits to receive dental services during the past 12 months. The mean dental spending for household members was 5,429,344 \pm $1,268,817$ Rials.

The results of the logistic regression model showed that the most important determinants of dental service utilization were the household income, gender, age, education level of the head of the household, and supplementary coverage. The results of our analysis showed that a higher age of the head of the household had a positive relationship with the utilization of dental services. Being a female head of the household $(\mathrm{OR}=0.39)$ and an increase in the household size $(\mathrm{OR}=0.9)$ led to a decline in the utilization of these services. Also, participants with higher income levels showed a higher chance of using dental services than the poorer ones (between 20 and 30 million Rials, OR = 1.13; above 30 million Rials, $\mathrm{OR}=1.66$ ). A higher level of education and the employment of the head of the household showed positive relationships with the utilization of dental services. Moreover, the results showed that people with supplementary health insurance coverage were more likely to use dental services than those without this coverage $(\mathrm{OR}=1.72)$.

Finally, the concentration index for the use of dental services was estimated at 0.207 with a standard deviation of 0.063 . Figure 1 demonstrates the concentration curve of the use of dental services. As evident in the figure, the concentration curve is below the equality line, which shows that inequality in the utilization of dental services is in the interest of high-income earners.

\section{Discussion}

The purpose of this study was to assess the utilization and demand for dental services and identify inequalities in the utilization of these services in Khorramabad city, Iran. Identifying such inequalities for evidence-based planning and policymaking is necessary to provide useful information about the characteristics of people who are less likely to use dental care and finally, to improve the use of such services among deprived socioeconomic classes.

The income elasticity of dental services was estimated to be 0.31 , which indicates that dental services are considered a necessity good in the basket of consumer goods; in other words, if the household income is reduced, the decline in demand for such services is relatively less than the reduction in income. This finding seems logical considering that $63 \%$ of demanded dental services were tooth extraction and filling and the community under study used a few luxurious dental services such as orthodontics. Also, low-income elasticity in society where there is no complete government and private insurance coverage for dental services may be due to the fact that the difference in the income level in the population under study is low and as a result, the difference in demand for dental care and the use of dental services among income groups is low. In a study by Grytten et al., income elasticity for dental services was estimated to be 0.17 (21), which showed that in our survey population, the effect of income on demand for dental services was greater. The findings of the study indicated that the main reason for the lack of seeking dental care was the high cost of these services. In other studies, regardless of the type of payment system and insurance system, costs were mentioned as important barriers to access to dental services (26). This situation represents a serious problem because if people stop seeking dental care services because of the lack of health insurance or financial ability, there will be long-term consequences for their oral health, which will eventually lead to imposing high health expenditures on the health system in the future (27).

The results of the regression model indicated a positive relationship between the household income and demand for dental services because high-income individuals have a higher ability to pay for health expenditures and as a result, they may be more likely to use the services. The study by Grytten et al. showed a significant positive correlation between the income of Norwegian households and the rate of utilization of dental services (21). A study in Australia showed that a $10 \%$ increase in income would result in an $8 \%$ increase in the use of dental services (28).

Piovesan et al. (29) evaluated the utilization of dental care services in 12-year-old children in Santa Maria, Brazil. They found that children with lower socioeconomic status were less likely to utilize dental services. In addition, in children with a better status, the utilization of public sector services was lower (29). Similarly, the results of a study performed in Indonesia indicated that despite that the lowest socioeconomic group was in the greatest need for dental services, the utilization of these services was higher among higher socioeconomic groups (30). The results of a study in Iran also revealed a positive relationship between household income and the utilization of dental services (7). Also, the results of a study carried out in Shiraz, Iran, indicated that the use of dental services in lowincome groups was lower than that of high-income groups and the rich had higher out-of-pocket payments for dental services (9). The results of these two studies are in line with the current study findings and show some kind of inequal- 


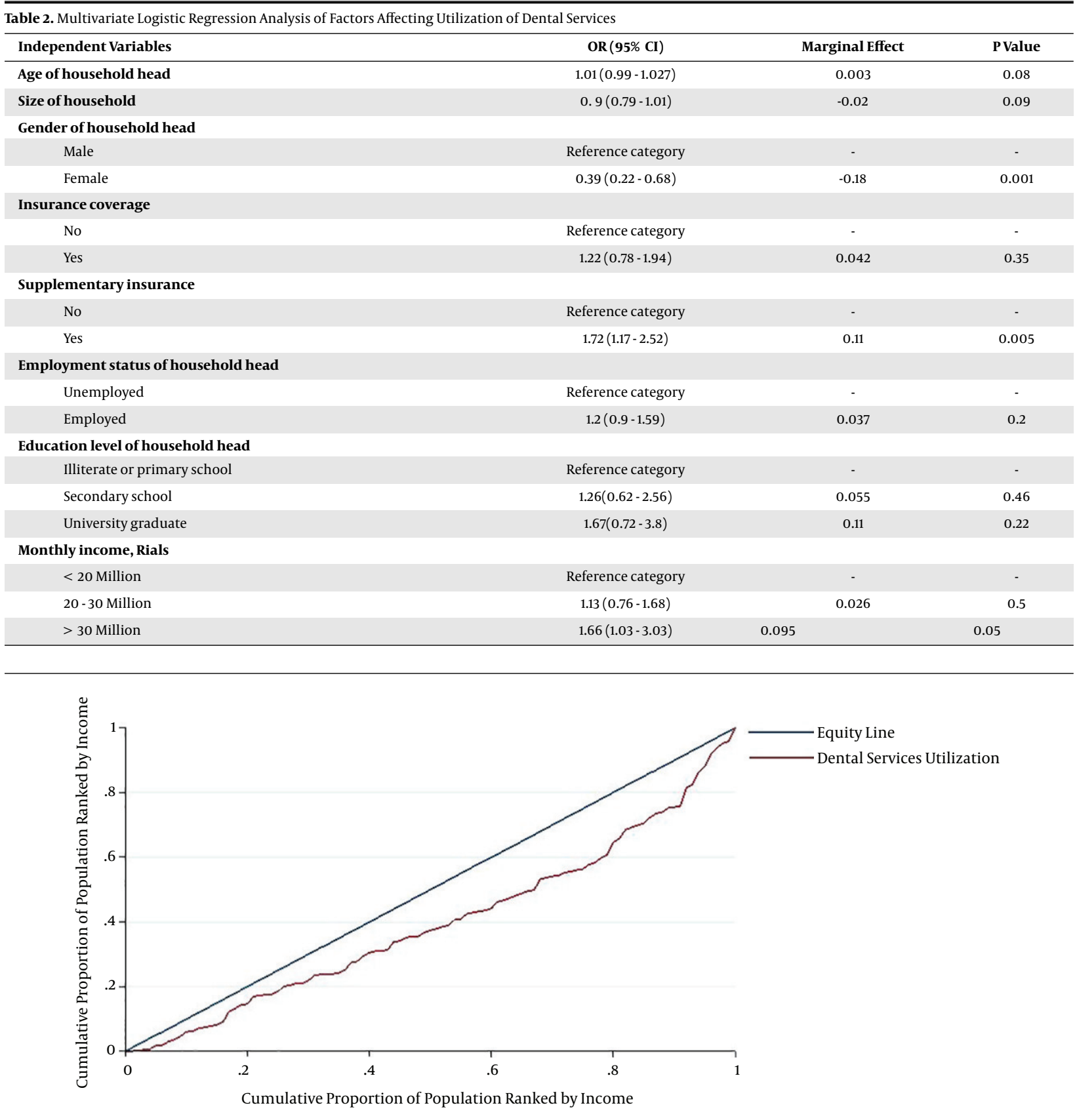

Figure 1. Concentration curve of the utilization of dental services

ity between the poor and the rich in the utilization of these services. A finding of our study was the increase in the utilization of dental services with increasing age of the head of the household, which is in concord with the findings of a study conducted by Benjakul and Chuenarrom in southern Thailand that showed age was one of the most important factors affecting the utilization of dental care (31). An- other study in Australia showed that the utilization of dental services increased with increasing age (32). Age is a capital good and people's health savings may decrease at a certain rate as age increases; consequently, to preserve health, the utilization of health care increases (33). In addition, age contains need elements and because of its correlation with wealth, it has enabling factors (34). A study by Rezaei et al. 
in Sanandaj also showed that age is one of the factors affecting the utilization of dental services (7).

In addition, we found that the employment status of the head of the household was one of the most important determinants of dental care utilization. The results of some studies also indicated that employed people seek health services more than non-employed individuals. Gholami et al. also concluded that occupation is one of the most important determinants of health (35). Employment seems to increase the chance of individuals to have insurance coverage, thereby increasing the utilization of health services. They also ascribed a positive relationship between the level of education of the head of the household and the rate of utilization of dental services. These results are similar to the findings of a study conducted in Belgium (36). Jang et al. showed that the probability of having an unmet dental need was higher in those having lower than secondary education (37). The positive impact of education on the utilization of dental services can be attributed to the knowledge of oral health and attitude towards the utilization of dental services since educated people have more knowledge about dental health than less educated ones (38). In addition, educated people usually belong to higher socioeconomic groups and therefore, are more likely to pay for dental care. However, a study in Japan showed that the level of education was not significantly associated with the utilization of dental care and this relationship was significant in preventive dental services only in the female group (39). Thus, further studies are proposed to determine the relationship between the level of education and the utilization rate of dental services.

Being a female head of household led to a reduction in the likelihood of using dental services, which could be as high as two-fold. First, households with a female head have lower income levels and consequently, are less likely to pay for health services, especially expensive dental services. As shown in a study performed in Indonesia and a study by Kim et al. in South Korea, due to economic difficulties, the chance of having unmet dental care needs is higher in women $(40,41)$. Second, women are more interested in their health than men and they use preventive services more than dental care services (39).

In alignment with our results, Rad et al. showed a positive relationship between insurance coverage and the utilization of dental services, but this relationship was not statistically significant, which was different from the results of previous studies. Perhaps this discrepancy is because most insurance schemes in Iran do not cover dental services. Insurance services should reduce the cost of services for people so that people can pay more for dental care. Studies have shown that dental services are price elastic services and a slight reduction in costs will lead to a sig- nificant increase in the utilization of these services (42).

Pizarro et al. investigated the effect of insurance coverage on the use of dental services and found that the use of these services expands as insurance coverage increases (43). The results showed that the probability of using dental services among households with supplementary insurance coverage was higher. An important reason for the increase in the likelihood of seeking and using dental services among these households is that this kind of insurance reduces household expenses and increases access to these services. This finding is in line with the results of previous studies, which showed that the probability of receiving dental services was higher among people with higher income levels and those with dental care insurance coverage $(44,45)$. One study showed that dental insurance services enhanced the likelihood of dental visits by $13 \%$ (46).

In this study, the concentration index was 0.277 , which indicates large inequality in the use of dental services in favor of the rich in the region. The finding suggests that policymakers of the Iranian health system reduce out-ofpocket payments for these services as far as possible if the government intends to improve access to dental services, especially for the poor, to achieve the goal of horizontal equity. Somkotra et al. studied the use of dental services in children after having access to public coverage in Thailand. In that study, the concentration index was estimated to be 0.069 , which shows a more equitable distribution of dental services in Thailand than in Iran (47).

Listl examined inequality in the use of dental services in 14 European countries. The results showed that the highest concentration index (0.3092) was in Poland and the lowest concentration index (0.0254) was in Germany (48).

In the current study, not only were the main determinants of the demand and utilization of dental services identified using the logistic regression method, but also income elasticity of the demand for dental services was estimated among Iranian households using the linear regression method. Furthermore, the index and the concentration curve were estimated to determine the amount of inequality in the utilization of dental services and the income groups that benefited from it. Study limitations should be considered when interpreting the results. First, the study was carried out in an urban area of Iran and the results cannot be generalized to other parts of Iran to estimate inequality in the whole country. Second, the findings of this study are based on cross-sectional data and therefore, there is no causal relationship between explanatory variables and the use of dental services; thus, the findings of the study should be interpreted with caution.

The results of this study provide insight into the various factors associated with the use of dental services and can, therefore, be used to develop targeted and strategic 
plans to improve access to these services. The results also showed inequality in the use of dental services between the poor and the rich such that individuals with a higher income level used dental services more, while the poor could not afford to use these services. Therefore, policymakers and health system planners must come up with solutions to reduce this inequality. For example, health insurance should increase the coverage of dental care in such a way that the access of the poor is increased and inequality between the poor and the rich is reduced.

\section{Acknowledgments}

The authors appreciate all participants in the study.

\section{Footnotes}

Authors' Contribution: Study concept and design: Soraya Nouraei Motlagh, Sheida Abbasi-Shakaram, Saman Ghasempour, Sara Hasanvand, and Mohammad Hasan Imani-Nasab. Analysis and interpretation of data: Soraya Nouraei Motlagh, Mohammad Hasan Imani-Nasab, and Razieh Bajoulvand. Drafting of the manuscript: Soraya Nouraei Motlagh and Sheida Abbasi-Shakaram. Critical revision of the manuscript for important intellectual content: Soraya Nouraei Motlagh, Saman Ghasempour, Mohammad Hasan Imani-Nasab, Sara Hasanvand, and Razieh Bajoulvand. Statistical analysis: Soraya Nouraei Motlagh and Sheida Abbasi-Shakaram.

Conflict of Interests: The authors declare that they have no conflict of interests.

Ethical Approval: Ethical approval code of our accepted article is: IR.LUMS.1396.1943.

Funding/Support: This study was funded by the Deputy of Research and Technology of Lorestan University of Medical Sciences (code: 1748).

Informed Consent: Informed consent was obtained from all participants in the study.

\section{References}

1. Hosseinpoor AR, Itani L, Petersen PE. Socio-economic inequality in oral healthcare coverage: Results from the World Health Survey. $J$ Dent Res. 2012;91(3):275-81. doi: 10.1177/0022034511432341. [PubMed: 22205634].

2. Jin LJ, Armitage GC, Klinge B, Lang NP, Tonetti M, Williams RC. Global oral health inequalities: Task group-periodontal disease. Adv Dent Res. 2011;23(2):221-6. doi: 10.1177/0022034511402080. [PubMed: 21490234].

3. Baelum V, van Palenstein Helderman W, Hugoson A, Yee R, Fejerskov O. A global perspective on changes in the burden of caries and periodontitis: Implications for dentistry. J Oral Rehabil. 2007;34(12):872906. discussion 940. doi: 10.1111/j.1365-2842.2007.01799.x. [PubMed: 18034671].
4. Elujoba AA, Odeleye OM, Ogunyemi CM. Traditional medicine development for medical and dental primary health care delivery system in Africa. Afr J Tradit Complement Altern Med. 2004;2(1). doi:10.4314/ajtcam.v2i1.31103.

5. Listl S, Galloway J, Mossey PA, Marcenes W. Global economic impact of dental diseases. J Dent Res. 2015;94(10):1355-61. doi: 10.1177/0022034515602879. [PubMed: 26318590].

6. Hoseinpour R, Safari HR. A review of statistics and information about the dentistry section of the country. Tehran, Iran: Iranian Dental Association; 2013.

7. Rezaei S, Ghahramani E, Hajizadeh M, Nouri B, Bayazidi S, Khezrnezhad F. Dental care utilization in the west of Iran: A cross-sectional analysis of socioeconomic determinants. Int J Hum Rights Healthc. 2016;9(4):235-41. doi: 10.1108/ijhrh-06-2016-0008.

8. Rezaei S, Woldemichael A, Zandian H, Homaie Rad E, Veisi N, Karami Matin B. Dental health-care service utilisation and its determinants in West Iran: A cross-sectional study. Int Dent J. 2018;68(3):176-82. doi: 10.1111/idj.12346. [PubMed: 29171015].

9. Homaie Rad E, Kavosi Z, Arefnezhad M. Economic inequalities in dental care utilizations in Iran: Evidence from an urban region. Med J Islam Repub Iran. 2016;30:383. [PubMed: 27493927]. [PubMed Central: PMC4972081].

10. Ghaderi H, Jamshidi R, Ghorbani AR. Estimation of dental services demand function of family in Sabzevar, Iran, in the urban area: 2007.J Health Adm. 2010;13(40):7-12.

11. Petersen PE. The World Oral Health Report 2003: Continuous improvement of oral health in the 21st century-the approach of the WHO Global Oral Health Programme. Community Dent Oral Epidemiol. 2003;31 Suppl 1:3-23. doi: 10.1046/j..2003.com122.x. [PubMed: 15015736].

12. Sisson KL. Theoretical explanations for social inequalities in oral health. Community Dent Oral Epidemiol. 2007;35(2):81-8. doi: 10.1111/j.1600-0528.2007.00354.x. [PubMed: 17331149].

13. Hessari H, Vehkalahti MM, Eghbal MJ, Samadzadeh H, Murtomaa HT. Oral health and treatment needs among 18-year-old Iranians. Med Princ Pract. 2008;17(4):302-7. doi: 10.1159/000129610. [PubMed: 18523398].

14. Nahvi M, Zarei E, Marzban S, Jahanmehr N. Utilization of dental services and its out-of-pocket payments: A study in dental clinics of Ramsar. J Mashhad Dent Sch. 2017;41(2):171-82.

15. Muirhead VE, Quinonez C, Figueiredo R, Locker D. Predictors of dental care utilization among working poor Canadians. Community Dent Oral Epidemiol. 2009;37(3):199-208. doi: 10.1111/j.16000528.2009.00471.x. [PubMed: 19508268].

16. Aday LA, Andersen R. A framework for the study of access to medical care. Health Serv Res. 1974;9(3):208-20. [PubMed: 4436074]. [PubMed Central: PMC1071804].

17. Grewal H, Verma M, Kumar A. Prevalence of dental caries and treatment needs in the rural child population of Nainital District, Uttaranchal. J Indian Soc Pedod Prev Dent. 2009;27(4):224-6. doi: 10.4103/09704388.57657. [PubMed: 19915273].

18. Andkhoie M, Pandovska-Pelivanova E, Emmanuel S, Lateef F, Szafron M, Farag ME. Demand and burden of dental care in Canadian households. Int J Health Econ Finance. 2014;6(9). doi: 10.5539/ijef.v6n9p73.

19. Guiney H, Woods N, Whelton H, Morgan K. Predictors of utilisation of dental care services in a nationally representative sample of adults. Community Dent Health. 2011;28(4):269-73. [PubMed: 22320064].

20. Bahadori M, Ravangard R, Asghari B. Perceived barriers affecting access to preventive dental services: Application of DEMATEL method. Iran Red Crescent Med J. 2013;15(8):655-62. doi: 10.5812/ircmj.11810. [PubMed: 24578831]. [PubMed Central: PMC3918188].

21. Grytten J, Holst D, Skau I. Demand for and utilization of dental services according to household income in the adult population in Norway. Community Dent Oral Epidemiol. 2012;40(4):297-305. doi: 10.1111/j.1600-0528.2011.00659.x. [PubMed: 22239170]. 
22. Locker D, Maggirias J, Quinonez C. Income, dental insurance coverage, and financial barriers to dental care among Canadian adults. J Public Health Dent. 2011;71(4):327-34. doi: 10.1111/j.17527325.2011.00277.x. [PubMed: 22320291].

23. Almasiankia A, Kavosi Z, Keshtkaran A, Jafari A, Goodarzi S. Equity in health care financing among Iranian households. Shiraz E Med J. 2015;16(11-2). doi: 10.17795/semj28653.

24. Rezapoor A, Roumiani Y, Azar FEF, Ghazanfari S, Mirzaei S, Asiabar AS, et al. Effective factors on utilization and access to health care: A population-based study in Kerman.J Health Adm. 2015;18(60).

25. Wagstaff A, O'Donnell O, van Doorslaer E. Quantitative techniques for health equity analysis. Washington, DC: World Bank Publications; 2007.

26. Hill KB, Chadwick B, Freeman R, O'Sullivan I, Murray JJ. Adult Dental Health Survey 2009: Relationships between dental attendance patterns, oral health behaviour and the current barriers to dental care. Br Dent J. 2013;214(1):25-32. doi: 10.1038/sj.bdj.2012.1176. [PubMed: 23306496].

27. Cruz G, Nunez G, Salinas A, Ramos E, Sanchez R. Factors associated with the use of dental health services in primary care in northeastern Mexico. J Oral Res. 2016;5(6):240-7. doi: 10.17126/joralres.2016.053.

28. Grytten J, Holst D. Do young adults demand more dental services as their income increases? Community Dent Oral Epidemiol. 2002;30(6):463-9. doi: 10.1034/j.1600-0528.2002.00016.x. [PubMed: 12453118]

29. Piovesan C, Antunes JL, Guedes RS, Ardenghi TM. Influence of selfperceived oral health and socioeconomic predictors on the utilization of dental care services by schoolchildren. Braz Oral Res. 2011;25(2):143-9. [PubMed: 21359493].

30. Maharani DA, Rahardjo A. Is the utilisation of dental care based on need or socioeconomic status? A study of dental care in Indonesia from 1999 to 2009. Int Dent J. 2012;62(2):90-4. doi: 10.1111/j.1875595X.2011.00095.x. [PubMed: 22420478].

31. Benjakul P, Chuenarrom C. Utilisation of dental care at the University Dental Hospital, Southern Thailand. Int Dent J. 2000;50(5):262-6. doi: 10.1111/j.1875-595x.2000.tb00563.x. [PubMed: 15988884].

32. Slack-Smith L, Hyndman J. The relationship between demographic and health-related factors on dental service attendance by older Australians. Br Dent J. 2004;197(4):193-9. discussion 190. doi: 10.1038/sj.bdj.4811571. [PubMed: 15375412].

33. Daryazadeh S, Kuhpayehzadeh J, Hashemzadeh M, Shajari J, Jafari A. Comparison of patients' demand and need to receive restorative dental services. Razi J Med Sci. 2015;21(127):52-60.

34. Manski RJ, Moeller JF, Chen H, St Clair PA, Schimmel J, Pepper JV. Wealth effect and dental care utilization in the United States. I Public Health Dent. 2012;72(3):179-89. doi: 10.1111/j.1752-7325.2012.00312.x. [PubMed: 22515635]. [PubMed Central: PMC3433846].

35. Gholami M, Nasiripoor AA, Maleki MR. The relation between social determinant of health with access to health services in Gonbad Kavoos. Community Health. 2016;3(1):54-65.

36. Van der Heyden JH, Demarest S, Tafforeau J, Van Oyen H. Socio- economic differences in the utilisation of health services in Belgium. Health Policy. 2003;65(2):153-65. doi: 10.1016/s0168-8510(02)00213-0. [PubMed: 12849914].

37. Jang Y, Yoon H, Park NS, Chiriboga DA, Kim MT. Dental care utilization and unmet dental needs in older Korean Americans. J Aging Health. 2014;26(6):1047-59. doi: 10.1177/0898264314538663. [PubMed 24925691].

38. Zhu L, Petersen PE, Wang HY, Bian JY, Zhang BX. Oral health knowledge, attitudes and behaviour of adults in China. Int Dent J. 2005;55(4):231-41. doi: 10.1111/j.1875-595x.2005.tb00321.x. [PubMed: $16167612]$.

39. Murakami K, Aida J, Ohkubo T, Hashimoto H. Income-related inequalities in preventive and curative dental care use among working-age Japanese adults in urban areas: A cross-sectional study. BMC Ora Health. 2014;14:117. doi: 10.1186/1472-6831-14-117. [PubMed: 25234486] [PubMed Central: PMC4176863].

40. Maharani DA. Inequity in dental care utilization in the Indonesian population with a self-assessed need for dental treatment. Tohoku J Exp Med. 2009;218(3):229-39. doi: 10.1620/tjem.218.229. [PubMed: 19561394].

41. Kim N, Kim CY, Shin H. Inequality in unmet dental care needs among South Korean adults. BMC Oral Health. 2017;17(1):80. doi 10.1186/s12903-017-0370-9. [PubMed: 28446178]. [PubMed Central: PMC5406911].

42. Meyerhoefer CD, Zuvekas SH, Manski R. The demand for preventive and restorative dental services. Health Econ. 2014;23(1):14-32. doi 10.1002/hec.2899. [PubMed: 23349123].

43. Pizarro V, Ferrer M, Domingo-Salvany A, Benach J, Borrell C, Pont A, et al. The utilization of dental care services according to health insurance coverage in Catalonia (Spain). Community Dent Oral Epidemiol. 2009;37(1):78-84. doi: 10.1111/j.1600-0528.2008.00439.x. [PubMed: 18782332].

44. Duncan L, Bonner A. Effects of income and dental insurance coverage on need for dental care in Canada. J Can Dent Assoc. 2014;80. e6. [PubMed: 25055239].

45. Manski RJ, Moeller JF, Chen H. Dental care coverage and use: Modeling limitations and opportunities. Am JPublic Health. 2014;104(2):e807. doi: 10.2105/AJPH.2013.301693. [PubMed: 24328635]. [PubMed Central: PMC3935710].

46. Cooper PF, Manski RJ, Pepper JV. The effect of dental insurance on dental care use and selection bias. Med Care. 2012;50(9):757-63. doi 10.1097/MLR.0b013e318255172d. [PubMed: 22525615].

47. Somkotra T, Vachirarojpisan T. Inequality in dental care utilisation among Thai children: Evidence from Thailand where universal coverage has been achieved. Int Dent J. 2009;59(6):349-57. [PubMed: 20162947].

48. Listl S. Income-related inequalities in dental service utilization by Europeans aged 50+. J Dent Res. 2011;90(6):717-23. doi: 10.1177/0022034511399907. [PubMed: 21508432]. [PubMed Central: PMC3318029]. 